FAZENDA BABILÔNIA

\section{Patrimônio, história e gastronomia}

Construída em fins do século XVIII, a fazenda Babilônia se destaca, hoje, pelo seu imenso valor histórico, preservado durante séculos. Tombada como patrimônio nacional pelo Iphan e inscrita no Livro de Belas Artes, no 480 , em 26/04/1965, conserva o extenso casarão, em estilo colonial, e diversos muros de pedras, construídos pelos escravos. Essa edificação, de porte majestoso, é sustentada por grossos esteios e vigas de madeiras, com paredes de adobe e pau-a-pique. Algumas dessas madeiras chegam a medir 2 palmos de largura e atravessam vãos livres de cerca de 15 metros. $\mathrm{O}$ enorme telhado, coberto com telhas-coxa é composto de caibros roliços de cerca de $20 \mathrm{~cm}$ de diâmetro, muito próximos uns dos outros. Todo esse madeirame é unido por encaixes precisos e cavilhas de madeiras. Muito pouco metal foi usado, havia carência desse material devido à dificuldade da importação ocasionada pela distância e o custo da longa viagem. Os pregos usados, principalmente nos assoalhos, são quadrados, feitos manualmente em bigornas. A casa segue um padrão conhecido como arquitetura colonial paulista pois era comum, durante o século $\mathrm{XIX}$, as fazendas paulistas construírem casas desse estilo, que tem como característica mais marcante a sua distribuição espacial, que permitia ao senhor vigiar e controlar toda a fazenda a partir de alguns poucos

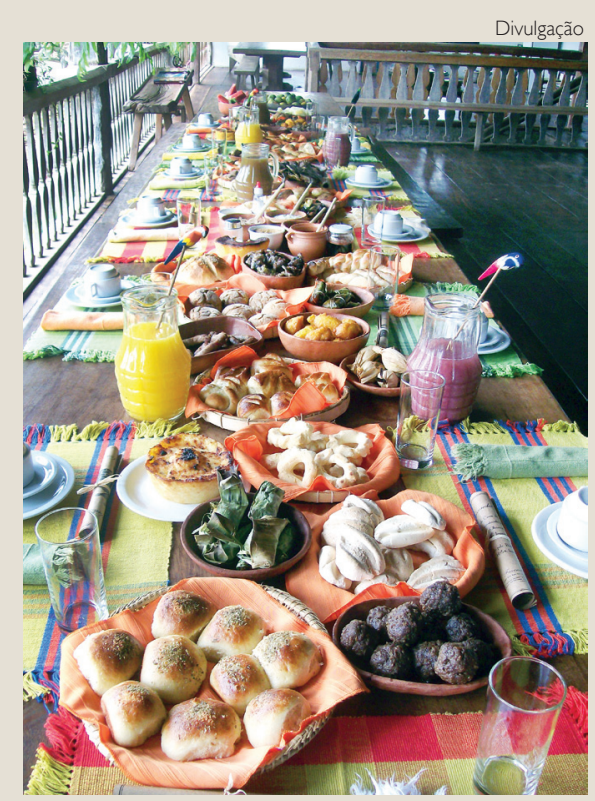

Café colonial oferecido na fazenda

lugares estratégicos da casa. No caso da fazenda Babilônia, da ampla varanda controlava-se toda a senzala e as edificaçôes externas, e da sala de jantar, rebaixa e a moenda.

Destaca-se dentro dessa grande construção, a capela, ainda toda original, localizada ao final da grande varanda, que acompanha toda a frente da casa. Dedicada a Nossa Senhora da Conceição e de pequenas dimensões, conserva o assoalho de madeira e os forros pintados com as imagens de São Joaquim e de Sant' Ana, emolduradas por elementos artísticos barrocos. O altar, estreito e ao fundo, é encimado por um pequeno nicho onde se encontra a imagem de Nossa Senhora da Conceição sobre um retábulo todo de madeira. Chama a atenção os diversos espelhinhos redondos, correntes pintadas e meialuas, provavelmente herança dos artistas escravos africanos. Na parede, contígua à casa, há uma janela treliçada que dá vista à sala. Deste modo, da sala se vêo altar. Era também uma maneira de contemplar as mulheres, que assistiam as missas acomodadas na sala, os homens assistiam, em pé, na varanda, e apenas o padre ficava dentro da capela.

O total do acervo dos objetos antigos só é possível ser conhecido com mais detalhes, numa visita à fazenda, passando horas conversando com a proprietária. A fazenda conta também com um pequeno museu com diversos objetos antigos, do tempo das mulas, das camas de tiras de couro e colchão de crina, quando se faziam velas de cera e as mulheres montavam em cilhões, carregando as tralhas em bruacas de couro duro.

A HISTÓRIA Em fins do século XVIII, mais precisamente em 1795, chega em Meia Ponte Joaquim Alves de Oliveira. Homem culto, nascido em 1770 em Pilar de Goiás, educou-se junto aos padres jesuítas em São Paulo e, desde moço, mostrou excelentes dotes para o comércio, fazendo fortuna no Rio de Janeiro. Ao voltar para Goiás, vislumbrou progresso no até então fervilhante arraial de Meia Ponte, que vinha sofrendo franca decadência de suas minas do ouro. Ele iniciou, então, a ousada empreitada de construir o engenho São Joaquim, primitivo nome da fazenda Babilônia que, segundo Pohl, em Viagem ao interior do Brasil, era "um dos maiores engenhos de açúcar do Brasil". Johann Baptist Emanuel Pohl (1782-1834), autor do livro, integrou a missão austríaca ao Brasil entre 1817 e 1821 e era médico, geólogo e botânico. Logo após 1800, o engenho São Joaquim já era considerado a maior empresa agrícola do estado de Goiás. Nessa fazenda, 
além da cana-de-açúcar, plantavase, em escala industrial, mandioca e algodão, para a produção da farinha e de fios para exportação. A Inglaterra, em plena Revolução Industrial, comprava toda a produção de algodão goiano, cuja fibra era considerada uma das melhores do mundo. A produção da fazenda era tão intensa que contava com cerca de 200 escravos, sendo 120 homens para o trabalho e 80 mulheres e crianças.

Um dos relatos mais significantes do livro é o do viajante francês August Saint-Hilaire: “...Daqui nos dirigimos para leste, subimos uma encosta bastante elevada e, depois de três quartos de légua, chegamos a um dos maiores engenhos de açucar do Brasil, o engenho do coronel Joaquim Alves,.. ”. Vale destacar, entre tantas informações relevantes, a importância do comendador Joaquim Alves, para Goiás e Centro-Oeste, também em relação aos escravos e à produtividade e o comércio de bens, em especial o algodão para exportação. Saint-Hilaire ainda descreve com maestria a estrutura da fazenda, com detalhes interessantes como a máquina de ralar mandioca, movida à água, e a organização das senzalas e oficinas.

Devido ao seu grau de empreendedorismo, o comendador pode ser comparado ao Barão de Mauá. Sua renda era muitas vezes superior à renda da província. Através da agricultura e do comércio conseguiu manter a então decadente Minas de Meia Ponte e transformá-la numa das principais cidades do estado. Por Meia Ponte passavam todas as "picadas de Goiás". Era o centro comercial de toda a província de Goiás,era a confluência das rotas comercias, recebia e despachava tropas para Cuiabá, Salvador e Rio de Janeiro. A tropa do comendador, de quase 300 muares, levava, além dos produtos da fazenda, como o algodão, açúcar e farinha de mandioca, produtos diversos produzidos por outros fazendeiros da região, como o próprio algodão, cuja cultura o comendador incentivava e ajudava na produção e no comércio. Além disso, ele trazia, dessas viagens comerciais, produtos essenciais, como sal e ferro, e outros tantos que lhe eram lucrativos, como tecidos finos e armas. Por ocasião das partidas de sua comitiva, que eram capitaneadas por seu genro, o sargento-mor Joaquim da Costa Teixeira, iam também, por conforto e segurança, aqueles que desejavam viajar para fora da província, tornando a comitiva uma empreitada solene, de longa duração, com muitos animais, carregamentos e muita gente. Para se ter ideia, gastava-se, em picadas pelo sertão, três meses de viagem para chegar a Salvador ou Rio de Janeiro, e no mínimo outros três meses para voltar.

IMPONÊNCIA DO COMENDADOR Apesar de não ser o foco deste texto, não há como deixar de fazer um relato sobre a imponente figura do comendador, que tinha a patente de tenente-coronel comandante Joaquim Alves de Oliveira. Comandante liberal, patriota e humanitário, comprou uma tipografia, a Typographia Oliveira, e editou o primeiro jornal do CentroOeste, a Matutina Meiapontense que circulou de 1830 a 1835 , montou a primeira biblioteca de Goiás e trouxe professores para a educação da população. Foi dele a iniciativa de promover a agricultura na pro- víncia goiana, num momento de decadência da mineração em toda a capitania de Goiás. Além de tudo era tido como homem sábio e justo, cuja efígie não deixou gravada, o que faz com que ninguém saiba ao certo como era o seu rosto.

Voltando à história da fazenda $\mathrm{Ba}$ bilônia, nela estiveram hospedados pessoas ilustres de referência para Goiás, como o próprio Saint-Hilaire, Pohl, Castelnau, D'alincourt, Cunha Mattos e outros. Porém sua decadência iniciou-se mesmo antes da morte do comendador, desiludido pela perda da esposa e filhos. Foi, pouco a pouco, se desinteressando pelos negócios e, em 1851, faleceu aos 81 anos. Como não deixou herdeiros, apesar de ter tido três filhos, legou o engenho São Joaquim, por testamento, ao seu braço-direito, seu genro e sargento-mor, Joaquim da Costa Teixeira.

Das construçôes e opulência da época do comendador, muito se perdeu. Sem a presença dele, o comércio decaiu e a fazenda diminuiu sua produção. Até que, em 1864, Joaquim da Costa Teixeira vendeu-a para o padre Simeão Estelita Lopes Zedes, bisavô da atual proprietária, Telma Lopes Machado.

Padre Simeão comprou, em 1864, parte da fazenda e encontrando lá, nessa ocasiāo, uma grande quantidade de agregados e escravos, achou que aquilo mais se assemelhava à $\mathrm{Ba}$ bilônia e desde então passou a chamar de fazenda Babilônia. Em 1876, adquiriu mais uma área e atravessou o fim do século XIX e início do século XX produzindo gado de corte. Meia Ponte não resistiu às transformaçōes do fim do século XIX, à 
morte do comendador, à Abolição da Escravatura e à Proclamação da República. Rotas comerciais foram deslocadas, fazendo com que a então próspera cidade perdesse $o$ status de centro mercantil, chegando ao século XX com a economia estagnada, baseada principalmente no gado de corte.

O tempo cumpriu seu papel e desfez a senzala e oficinas, muros e estábulos, sobrando, por determinação da família, o belo casarão, sede da fazenda, com a casa, capela, varanda e o pátio do antigo engenho abrigados por um vasto telhado de duas águas de grandes telhas de barro. Devido à histórica importância, a casa e suas dependências foram tombadas em 1965.

Com a construção de Brasília e o incremento do turismo em Pirenópolis, a fazenda Babilônia se tornou, gradativamente, referência histórica e, desde 1997, por iniciativa da atual proprietária, foi aberta à visitação.

Hoje, a fazenda Babilônia, além de trabalhar com pecuária, mantém o belo casarão, que preserva ainda cerca de $80 \%$ de sua originalidade, com grossas madeiras expostas, a capela, o pequeno museu de objetos antigos, sua história e o seu fabuloso café colonial, que a fazem a mais representativa fazenda histórica de Goiás, sendo objeto de estudo para teses de graduação e mestrado, pesquisas na área de arqueologia e história, destino de grupos de estudantes de todos os níveis, do médio ao superior, nas áreas de arquitetura, história, cultura e gastronomia.

Telma Lopes Machado é descendente dos antigos proprietários da fazenda Babilônia. telmafazendababilonia@yahoo.com.br

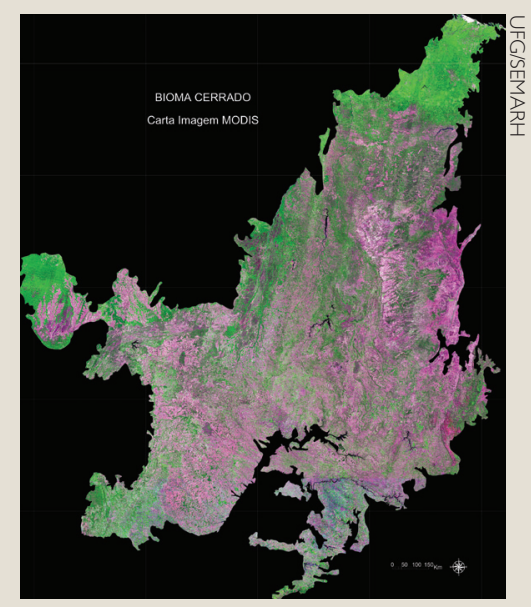

LAPIG

Uma década

de monitoramento ambiental

Desde 1995, o Laboratório de Processamento de Imagens e Geoprocessamento (Lapig) da Universidade Federal de Goiás (UFG), vinculado ao Instituto de Estudos Socioambientais (lesa), contribui de forma decisiva com o desenvolvimento acadêmico e científico do país, através de pesquisas ambientais realizadas em nível de graduação e pós-graduação (mestrado e doutorado), vinculadas ao estudo de ecossistemas por meio do sensoriamento remoto e de análises espaciais.

A partir da última década, porém, com o advento de novas técnicas de geoprocessamento e de sensores orbitais, 0 laboratório passa a responder pelo monitoramento da cobertura vegetal e do uso do solo em grandes biomas, como o Cerrado e a Amazônia. Um desses sensores é o Modis (Moderate Resolution
Imaging Spectroradiometer), com o qual é possível cobrir grandes extensões territoriais, com poucas cenas e elevada frequência de imageamento. Atualmente, dentre as principais pesquisas do Lapig, destaca-se o levantamento dos desmatamentos em todo o Cerrado (uma área de 2 milhões de km2, presente em mais de 10 estados brasileiros), realizado através do projeto Siad (Sistema Integrado de Alerta de Desmatamentos) - como mostra a figura 1 - , do qual são geradas análises de cunho físico, ecológico e socioeconômico.

Outros projetos, conduzidos especificamente para esse bioma, envolvem a análise dos impactos da conversão do uso da terra sobre os recursos hídricos da região, o mapeamento e a caracterização biofísica de áreas de pastagens cultivadas, a caracterização das áreas desmatadas (expansão de áreas agrícolas), monitoramento de queimadas/precipitação, além de estudos relacionados com a modelagem de cenários futuros para o Cerrado, em termos da ocupação antrópica e da respectiva governança ambiental. Uma grande base de dados geográfica pode ser acessada de forma online através do portal do laboratório na internet (www.lapig.iesa.ufg.br), com a disponibilização gratuita de mapas, imagens de satélite, artigos científicos, dissertações, teses e notícias.

Manuel E. Ferreira Email: manuel@iesa.ufg.br Ivonaldo F. Duarte Email:von_naldo@yahoo.com.br 